Trinity University

Digital Commons@ Trinity

Biology Faculty Research

Biology Department

$12-2010$

\title{
The Burden of Motherhood: The Effect of Reproductive Load on Female Lizard Locomotor, Foraging, and Social Behavior
}

Michele A. Johnson

Trinity University, mjohnso9@trinity.edu

J.L. Caton

R. E. Cohen

J.R. Vandecar

J.Wade

Follow this and additional works at: https://digitalcommons.trinity.edu/bio_faculty

Part of the Biology Commons

\section{Repository Citation}

Johnson, M.A., Caton, J.L., Cohen, R.E., Vandecar, J.R., \& Wade, J. (2010). The burden of motherhood: The effect of reproductive load on female lizard locomotor, foraging, and social behavior. Ethology, 116(12), 1217-1225. doi: 10.1111/j.1439-0310.2010.01840.x

This Article is brought to you for free and open access by the Biology Department at Digital Commons @ Trinity. It has been accepted for inclusion in Biology Faculty Research by an authorized administrator of Digital Commons @ Trinity. For more information, please contact jcostanz@trinity.edu. 


\title{
The Burden of Motherhood: The Effect of Reproductive Load on Female Lizard Locomotor, Foraging, and Social Behavior
}

\author{
Michele A. Johnson*, $\dagger$, Jessica L. Caton $\uparrow$, Rachel E. Cohen $\dagger$, Joseph R. Vandecar $\ddagger$ \& Juli Wade $\uparrow, \uparrow, \S$ \\ * Department of Biology, Trinity University, San Antonio, TX, USA \\ $\uparrow$ Department of Zoology, Michigan State University, East Lansing, MI, USA \\ \$ Department of Psychology, Michigan State University, East Lansing, MI, USA \\ $\S$ Neuroscience Program, Michigan State University, East Lansing, MI, USA
}

\section{Correspondence}

Michele A. Johnson, Department of Biology,

Trinity University, San Antonio, TX 781212,

USA.

E-mail: michele.johnson@trinity.edu

Received: August 23, 2010

Initial acceptance: August 30, 2010

Final acceptance: September 1, 2010

(L. Ebensperger)

doi: 10.1111/j.1439-0310.2010.01840.x

\begin{abstract}
The costs of reproduction, involving demands associated with both current and future reproductive efforts, may place a substantial burden on females. However, animals may minimize these costs by modifying their behavior across the reproductive cycle. We examined the effects of reproductive load on three types of behavior (locomotion, foraging, and social displays) in green anole lizards (Anolis carolinensis) by comparing egg, follicle, and oviduct mass and volume with field observational data. We found that female locomotor and social display behaviors decreased as reproductive load increased, suggesting behavioral modification in these traits, but we detected no relationship between foraging and reproductive load. We also examined these relationships across eight $\mathrm{An}$ olis species using a phylogenetically informed analysis and found no associations between the evolution of reproductive load and any of the three behaviors. These results suggest that the evolution of increased reproductive load is not associated with the interspecific variation in behavior across the anoles and may result from varying life history traits or selective ecological pressures across species.
\end{abstract}

\section{Introduction}

Across reproductive cycles, females experience many physical and physiological changes. These changes can be costly, potentially resulting in a female foregoing survival or future reproductive success in favor of current reproductive efforts. Life history models assume such trade-offs between current and future reproduction (e.g., Stearns 1989; Roff 1992; Rosenheim 1999), and an extensive literature on the performance, behavioral, and survival effects of pregnancy or gravidity (carrying internally developing eggs) supports these models (reviewed in Schwarzkopf 1994). However, females may decrease potential reproductive costs by modifying their behavior (Brodie 1989). These modifications may involve changes between reproductive and non- reproductive states, as well as changes that occur within a reproductive cycle. In this study, we focus on the latter.

The most commonly investigated behavioral modifications by reproductive females involve locomotion. Decreases in sprint speed (Sinervo et al. 1991; Olsson et al. 2000; Shine 2003a; Goodman 2006), endurance (Miles et al. 2000; Zani et al. 2008), and acceleration (Rodewald \& Foster 1998; Scales \& Butler 2007) are physical consequences of the burden of gravidity. Because they are less able to escape by fleeing, females with larger reproductive loads (mass of developing offspring) may be particularly susceptible to predation (Shine 1980), and reduced locomotion can be associated with predator avoidance. For example, gravid sticklebacks manage predation risks by remaining closer to refuges than non-gravid 
females, reducing the distance they must flee if attacked (Rodewald \& Foster 1998), and gravid females of several lizard species rely on crypsis more than flight (Bauwens \& Thoen 1981; Lecomte et al. 1993). Locomotion may also decrease because pregnant or gravid females spend more time basking (Shine 1980). In lizard species, maintenance of higher body temperatures allows oviductal eggs to develop at a faster rate (Schwarzkopf \& Shine 1991; Schwarzkopf 1994). However, basking can also increase predation risk, as this behavior generally occurs in exposed locations.

Foraging may also be affected by reproductive load, as pregnant or gravid females in many species consume less prey than other females (Shine 1980; Brodie 1989; Weeks 1996; Lin et al. 2008), despite their general increase in energy expenditure (Angilletta \& Sears 2000), particularly during locomotion (Schwarzkopf 1994; Miles et al. 2000). This lower food intake has been attributed to the negative influence of gravidity on foraging ability and the increased vulnerability to predation while foraging. Alternatively, these results may be because of the limited abdominal space available for food in reproducing females. Pregnancy greatly compresses a female's internal organs in many species and likely constrains the amount of food a female may consume (Weeks 1996; Weiss 2001; Munns \& Daniels 2007).

Reproductive load may also affect social display behavior (Nunez et al. 1997). Diminished movement by gravid females would likely result in fewer interactions with conspecifics. Displays also increase vulnerability to predation, and if gravidity further increases predation risk, then gravid females may display less to moderate vulnerability to attack. This association between display behavior and reproductive load has, to our knowledge, not yet been tested.

Lizards in the genus Anolis (anoles) provide an excellent opportunity to examine the effects of gravidity on the frequency of these three behaviors (locomotor movements, foraging, and social display). One can address this question within species, as female anoles exhibit extensive behavioral variation that may be associated with reproductive load (Nunez et al. 1997). In addition, comparison across species allows one to determine the extent of such potential relationships, for example whether behavioral variation depends on the burden of gravidity, or whether other factors such as habitat specialization (i.e., ecomorphology; reviewed in Losos 2009) are greater influences. This genus is a particularly good model for addressing this issue, as species in diverse habitats differ in traits such as foraging, antipredator, and territorial strategies (Losos 2009), yet anole species exhibit generally the same reproductive strategy. Most species breed from early spring to late summer (Licht \& Gorman 1970; Sanger et al. 2008), with females laying a single-egg clutch every 1-4 wk (Andrews \& Rand 1974), so animals at various reproductive stages are simultaneously available. Eggs and offspring receive no parental care, so the effects of gravidity can be examined without any influence of behavior toward previous offspring. Despite the lack of variation in clutch size in anoles, the relative reproductive load varies extensively across species. Across the genus, anoles have negative egg mass allometry, such that species with smaller body mass have relatively heavier eggs (Kratochvíl \& Kubička 2007). These traits allow us to directly compare behavioral traits across species that differ in ecology and relative reproductive load, but not in clutch size.

Here, we present results in which we examine both intraspecific and interspecific associations between behavior and reproductive load in unmanipulated female lizards in their natural environments. In Study 1, we examined the implications of reproductive load on behavior within Anolis carolinensis, the green anole (Fig. la), and hypothesized that locomotor, feeding, and social display behaviors would decrease in individuals bearing increased reproductive loads. In Study 2, we provide the first comparative study that addresses whether associations between reproductive load and these behaviors have evolved across eight species of anoles.

\section{Materials and Methods}

Study 1: Reproductive Load and Female Behavior in Anolis carolinensis

We collected behavioral and morphological data during the A. carolinensis breeding season in May 2008 in Jean Lafitte Historic Park, Barataria Preserve, Louisiana USA $\left(29^{\circ} 47.22^{\prime} \mathrm{N}, 90^{\circ} 6.53^{\prime} \mathrm{W}\right)$. We located 20 adult females by walking through the forest until finding an undisturbed animal. We performed 22- to $180-\mathrm{min}$ focal observations (average $=113 \mathrm{~min}$, standard error $=8.3 \mathrm{~min}$ ) between 0800 and 1830 , recording locomotion (crawls, runs, and jumps), social displays (dewlap extensions, head bobs, and push-ups), and foraging (prey capture), (as in Johnson et al. 2010). For each lizard, we calculated rates of each behavior (occurrence per min) for use in statistical analyses. 
Fig. 1: (a) Female Anolis carolinensis. (b) Anolis carolinensis female with an atypically large load of two oviductal eggs (indicated with asterisks; majority of shell has formed for egg on the right; egg on left is just beginning to shell) and one large yolking ovarian follicle (indicated with the arrow).
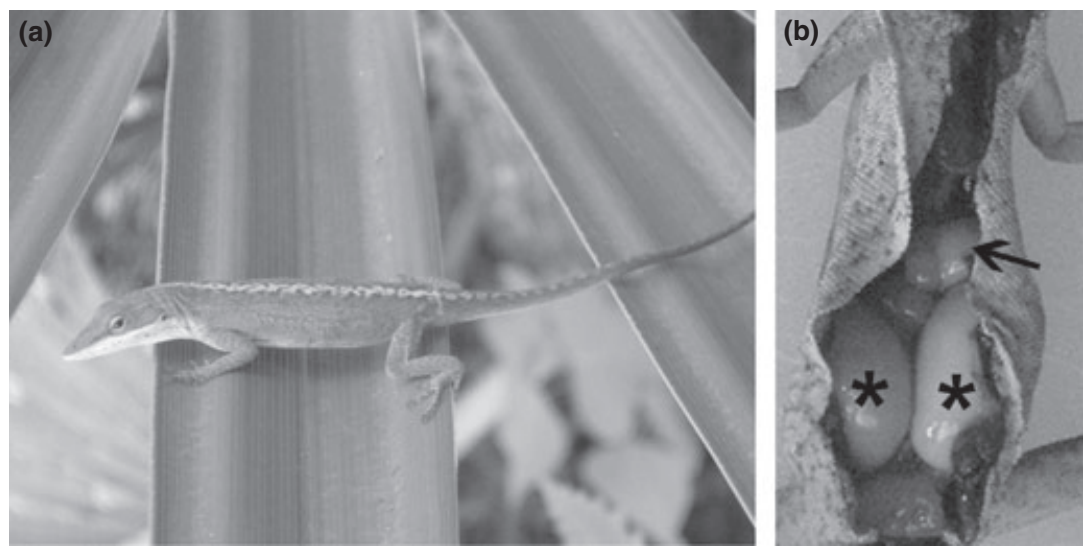

Immediately after each observation, we captured focal animals by noose and measured mass and snout-vent length (SVL). We harvested all reproductive tissues, including eggs, yolking and non-yolking follicles, and oviducts. We stored tissues on dry ice until returning to the laboratory, where they were stored at $-80^{\circ} \mathrm{C}$.

To determine reproductive load, we allowed the frozen tissues (eggs, follicles, and oviducts) to thaw at room temperature for $24 \mathrm{~h}$, by which point all obvious liquid had evaporated. We measured the mass of all reproductive tissue for each female ('dry' mass). To estimate volume, we measured the length $(L)$ and diameter $(B)$ of each egg (occasionally females had more than one developing egg, Fig. lb) using digital calipers and used these measures in the ellipsoid volume equation (Preston 1974)

$\frac{\Pi}{6} \times L B^{2}$.

For spherical yolking follicles, we measured the diameter $(B)$ of the follicle and used the equation

$\frac{4}{3} \Pi \times B^{2}$.

We summed all egg and follicle volumes for each female.

To determine the relationship between reproductive load and locomotor behavior, we conducted a principal components analysis (PCA) using a correlation matrix to reduce the number of variables in subsequent analyses. This PCA included run, crawl, and jump rates and yielded one PC with an eigenvalue greater than 1 , on which all locomotor behaviors loaded highly and positively (Table 1). Social display behavior was measured as the total rate of display behaviors (dewlap extensions, head bobs, and pushups) per min, and foraging was measured as the rate
Table 1: Results from principal component analyses on locomotor behaviors

\begin{tabular}{lcc}
\hline & PC1, Anolis carolinensis & PC1, 8 species \\
\hline Runs & 0.906 & 0.855 \\
Crawls & 0.883 & 0.565 \\
Jumps & 0.911 & 0.770 \\
Eigenvalue & 2.43 & 1.64 \\
Proportion variance & 81.0 & 54.8 \\
\hline
\end{tabular}

$\mathrm{PC}$, principal component.

of prey capture per min. Prior to analysis, two outliers (individuals that displayed $>+2$ SD from the mean) were removed from the analysis of social display. We conducted regression analyses in which either total dry mass of reproductive tissues or total egg and follicle volume was the independent variable, and the locomotor PC, prey capture rate, or social display rate was the dependent variable. We included female mass as a covariate to control for the potential relationship between female size and egg size. Finally, we used Pearson correlations to evaluate relationships among female SVL and mass, dry mass of reproductive tissues, and total egg and follicle volume.

\section{Study 2: Evolution of Reproductive Load and Female Behavior Across Anolis Species}

To determine whether reproductive load and behavioral modifications have evolved across anole species (as opposed to Study 1, in which we determined whether individuals with greater reproductive loads modify their behaviors within one species), we measured reproductive tissues collected from 10 adult females of seven additional species: Anolis bahorucoensis, Anolis coelestinus, Anolis cybotes, and Anolis olssoni from Barahona, Dominican Republic, and Anolis grahami, Anolis lineatopus, and Anolis valencienni from the 
north coast of Jamaica. We collected eggs and associated tissues, female mass, and SVL in the summer breeding season during tissue harvesting for Johnson \& Wade (2010) and stored the tissues at $-80^{\circ} \mathrm{C}$. We determined a "wet" mass of all reproductive tissues (after tissues thawed for $30 \mathrm{~min}$ ) and used this to estimate relative clutch mass [RCM: the ratio of wet mass of reproductive tissues to total female mass as in Shine (1980) and Sinervo et al. (1991)] carried by females of each species at the time of euthanasia. This measure allowed comparison of reproductive load in anoles to other lizard species (see Discussion). We then measured dry mass and volume of tissues in the same manner as for $A$. carolinensis.

Behavioral data for Caribbean species were obtained from Johnson (2007) and Johnson et al. (2008) and were collected during focal observations on 13-36 individuals per species as described earlier. Thus, individuals for which behavioral data were collected were not the same as those used in measurements of reproductive load. A species average was calculated for each of the three behavior categories. We conducted a PCA to obtain a locomotor variable as described previously, again extracting only one PC with an eigenvalue $>1$ (Table 1).

With morphological and behavioral data from all eight species (including A. carolinensis), we calculated phylogenetically controlled independent contrasts (Felsenstein 1985) using the Nicholson et al. (2005) anole phylogeny with branch lengths made proportional to time using the program r8s (Sanderson 2003) and pruned to include only the species in this study. Contrasts for female mass, dry mass of reproductive tissue, locomotor PC, social display rate, and prey capture rate were calculated using the program IDC (Revell 2006). All contrasts were adequately standardized (Garland et al. 1992) except those for female mass, which were recalculated after logarithmically transforming branch lengths plus a value of 1 . The contrasts were used in regression analyses (forced through the origin) to determine the relationship between dry mass of the reproductive tissue and each of the behaviors, again controlling for female mass. To determine interspecific relationships among female SVL and mass, dry mass of reproductive tissues, and total egg and follicle volume, we used uncentered correlations (correlations that assume the mean is zero, analogous to forcing a regression through the origin) of the contrast data, with p-values obtained from regressions forced through the origin for each pair of variables. We also performed parallel analyses to those described above using raw (non-phylogenetic) data.

\section{Ethical Note}

All research was conducted under Michigan State University's Institutional Animal Care and Use Committee protocol number 01/07-006-00. Tissues were collected under permits from the National Environment \& Planning Agency in Jamaica (18/27), the Secretaria de Estado de Medio Ambiente y Recursos Naturales in the Dominican Republic (0001023), the United States National Park Service (JELA-2008-SCI003) and the Louisiana Department of Wildlife and Fisheries (LNGP-08-059).

\section{Results}

Study 1: Reproductive Load and Female Behavior in Anolis carolinensis

Within A. carolinensis, measures of reproductive load were associated with variation in some female behaviors but not others. Specifically, reproductive tissue mass and rates of locomotor and social display behaviors were negatively correlated, but prey capture rates were not related to reproductive tissue mass (Table 2; Fig. 2). Female mass was also associated with social display behaviors, but in the opposite direction from reproductive load (Table 2), such that larger females produced more displays, but females with increased reproductive load displayed less. Results from regression with the volumes of eggs and follicles were identical (not shown).

Measures of female size and reproductive load were positively correlated as follows: female mass

Table 2: Regression analyses for Anolis carolinensis reproductive load and behavior

\begin{tabular}{llllll}
\hline & $R^{2}$ & df & $F$ & $\beta$ & $p$ \\
\hline $\begin{array}{l}\text { Locomotor behavior PC } \\
\quad \text { Regression }\end{array}$ & 0.33 & 2,17 & 4.19 & & $\mathbf{0 . 0 3 3}$ \\
$\quad$ Female mass & & & & 0.468 & 0.057 \\
$\quad$ Reproductive tissue mass & & & & -0.641 & $\mathbf{0 . 0 1 2}$ \\
$\begin{array}{l}\text { Social display } \\
\quad \text { Regression }\end{array}$ & 0.45 & 2,15 & 6.21 & & $\mathbf{0 . 0 1 1}$ \\
$\quad$ Female mass & & & & 0.541 & $\mathbf{0 . 0 2 7}$ \\
$\quad$ Reproductive tissue mass & & & & -0.753 & $\mathbf{0 . 0 0 4}$ \\
Prey capture rate & 0.12 & 2,17 & 1.18 & & 0.333 \\
$\quad$ Regression & & & & 0.056 & 0.832 \\
$\quad$ Female mass & & & & -0.373 & 0.173 \\
$\quad$ Reproductive tissue mass & & & & & \\
\hline
\end{tabular}

Significant $p$-values are indicated in bold font.

PC, principal component.

anclusion of the two social display outliers removed (see Methods) results in no relationship between display and egg mass, $p>0.5$. 

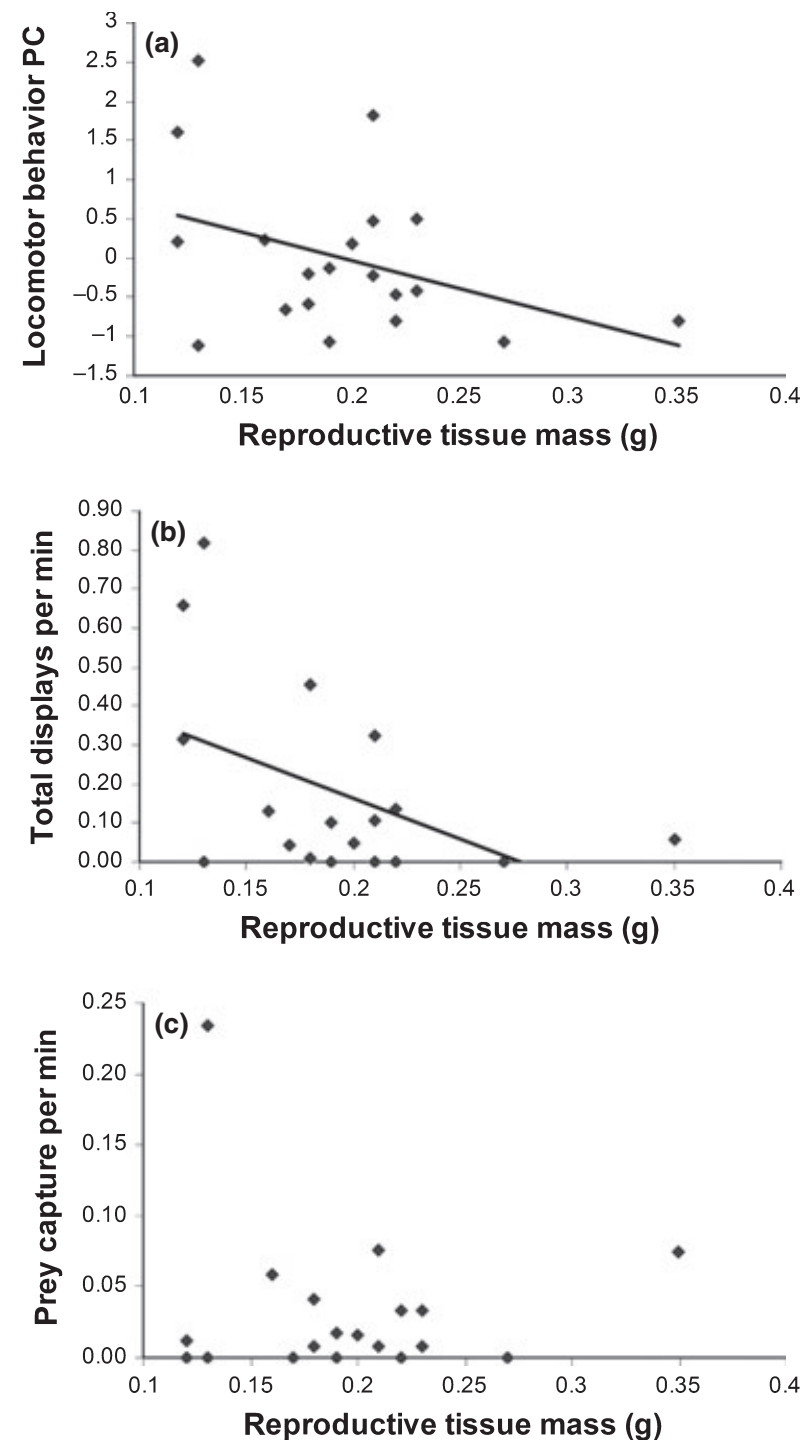

Fig. 2: Reproductive tissue mass of individual Anolis carolinensis plotted against three behavioral rates: (a) locomotion, (b) social displays, and (c) prey capture.

and reproductive tissue mass $(r=0.50, p=0.025)$, female mass and total egg and follicle volume $(r=0.51, \mathrm{p}=0.053)$, and reproductive tissue mass and egg and follicle volume $(r=0.93, \mathrm{p}<0.001)$. Thus, heavier females had larger, heavier eggs. Female SVL was not correlated with any other measures (all p >0.4).

Study 2: Reproductive Load and Female Behavior Across Anolis Species

Contrasts of the three behaviors measured were not associated with contrasts of reproductive tissue mass or female mass (Table 3). Analysis using raw (non-
Table 3: Regression analyses for independent contrasts of reproductive load and behavior across eight Anolis species

\begin{tabular}{llllll}
\hline & $R^{2}$ & df & $F$ & $\beta$ & $p$ \\
\hline $\begin{array}{l}\text { Locomotor behavior PC } \\
\quad\end{array}$ & 0.308 & 2,5 & 1.11 & & 0.398 \\
$\quad$ Regression & & & & 0.399 & 0.590 \\
$\quad$ Female mass & & & & 0.175 & 0.811 \\
$\quad$ Reproductive tissue mass & & & & & \\
Social display & 0.537 & 2,5 & 2.90 & & 0.146 \\
$\quad$ Regression & & & & -0.134 & 0.823 \\
$\quad$ Female mass & & & & 0.842 & 0.198 \\
$\quad$ Reproductive tissue mass & & & & & \\
Prey capture rate & 0.265 & 2,5 & 0.90 & & 0.464 \\
$\quad$ Regression & & & & 0.469 & 0.542 \\
$\quad$ Female mass & & & & 0.053 & 0.944 \\
$\quad$ Reproductive tissue mass & & & & &
\end{tabular}

PC, principal component.

phylogenetic) data produced identical results (not shown). Therefore, the evolution of increased reproductive investment was not associated with modifications of locomotor, social display, or foraging behavior. As for the data within A. carolinensis, results from egg and follicle volume were identical (not shown).

Contrasts of female size and reproductive load were correlated across the eight species as follows: female mass and reproductive tissue dry mass $(r=0.87, \mathrm{p}=0.024)$, female mass and egg and follicle volume $(r=0.87, \mathrm{p}=0.015)$, and reproductive tissue mass and egg and follicle volume $(r=0.95$, $\mathrm{p}=0.001)$. Thus, females of larger species had larger, heavier eggs than females of smaller species, and heavier eggs were larger in volume. Contrasts of female SVL were positively correlated with female mass $(r=0.79, \mathrm{p}=0.019)$ but not reproductive tissue mass or volume (both $\mathrm{p}>0.06$ ). Again, results from analyses with non-phylogenetic data were identical (not shown).

The range of RCM across these species was 0.0510.128 (Table 4). On average, females of most species had one shelling egg and one large yolking follicle (>2 $\mathrm{mm}$ in diameter) at the time of capture.

\section{Discussion}

Our results indicate that female $A$. carolinensis with larger reproductive loads perform less frequent locomotion and fewer social displays than females with smaller reproductive loads. However, we did not find evidence of trade-offs between gravidity and foraging in A. carolinensis, suggesting that the effects of increased reproductive load are relatively selective. Similar relationships may indeed exist within each 
species in the genus Anolis; however, our phylogenetic analysis of relationships between reproductive load and behavior did not reveal associations between these traits at the interspecific scale. Thus, while reproductive load is clearly an important cause of variation within the reproductive cycle in A. carolinensis, it does not appear to influence the evolution of locomotor or display behavior among species. Several hypotheses may explain the differences in associations between reproductive load and behavior at the specific and generic levels.

\section{Life History Traits may Influence Reproductive Investment}

First, Anolis lizards exhibit life history traits that may make them less vulnerable to reproductive costs. In particular, these lizards are gravid throughout long breeding seasons, and they must be able to perform at a sufficient level to procure prey and meet other needs while gravid. If resources are depleted during gravidity, females may be unable to recover and continue reproducing (Schwarzkopf 1994). The lack of modification of prey capture with increased reproductive load in A. carolinensis is consistent with this idea. In contrast, gravidity appears to either constrain individual A. carolinensis females' locomotor and display behavior or require gravid females to move and display less frequently to moderate the impacts of reproductive load (see Introduction).

The fixed single-egg clutch across anole species may induce a constraint to invest less in each clutch than many other lizards (Andrews \& Rand 1974; but see Cox $\&$ Calsbeek 2010). The RCM range for anoles (Table 4) is far smaller than that of a skink (Carlia rubrigularis) with fixed two-egg clutches $(\mathrm{RCM}=0.238$; Goodman 2006) and side-blotched lizards (Uta stansburiana) with variable clutch sizes $(\mathrm{RCM}=0.476$; Miles et al. 2000). The relatively low investment per clutch in anoles may allow them to avoid behavioral trade-offs endured by other taxa (Kratochvíl \& Kubička 2007). Our interspecific data are consistent with this idea, as anole species with greater reproductive loads did not locomote, forage, or display less than those with smaller loads.

\section{Interspecific Ecological Differences may Shape Reproductive Investment and Behavior}

The species in this study may experience selective pressures that cause differing behaviors to be beneficial under high reproductive loads. While they exhibit similar reproductive strategies, anole species vary in many traits, including microhabitat use (Williams 1983; Losos 1992), foraging modes (Johnson et al. 2008), and territorial strategies (Johnson et al. 2010), all of which are associated with ecomorphological variation. The behavioral variation among gravid females in this genus may be more due to these ecological differences than to reproductive load. For example, individuals of species that experience low overlap with conspecifics (e.g., A. olssoni, A. bahorucoensis) may perform few social displays (Johnson et al. 2010), regardless of reproductive load. In addition, species with relatively active foraging strategies may move more frequently than species with sit-and-wait strategies. Across lizards, sit-and-wait foragers generally have higher RCM than active foragers (Miles et al. 2007); however, this pattern is not seen within our data. Anolis cybotes and A. lineatopus are classic sit-and-wait foragers, with the other species in this study exhibiting a range of relatively more active foraging strategies (Johnson et al. 2008). Yet, these two species have the lowest RCM in this group (Table 4).

Interestingly, the two species with the highest reproductive loads in this study, A. bahorucoensis (with an average RCM of 0.128 ) and A. carolinensis (with an average of 1.0 egg and 1.7 yolking follicles per female; Fig. lb), have very different ecologies. Anolis bahorucoensis is a small-bodied lizard that lives in grasses and bushes in montane Dominican Republic (Fitch \& Henderson 1987), while A. carolinensis is a much larger lizard, generally occurring on tree trunks in the southeastern United States (Nunez et al. 1997). There is no clear explanation for why these two species, and not others, would invest so heavily in reproduction.

In addition, species in which females have relatively high reproductive loads may have evolved mechanisms to avoid behavioral trade-offs. For example, gravid Iguana iguana locomote frequently, even while bearing clutches up to $63 \%$ of their nongravid body mass. These females offset this load by increasing the mechanical power they produce during locomotion (Scales \& Butler 2007). Our current data cannot address the mechanisms of behavioral trade-offs among anoles, but it is an intriguing hypothesis for future study.

\section{Behavioral Modifications During Gravidity may be Non-essential}

Finally, behavioral modifications may be unnecessary for gravid females in some species. If so, some species of anoles may change their behavior within a 
Table 4: Average reproductive traits (and standard errors), for females of eight anole species

\begin{tabular}{lclll}
\hline Species & RCM & $\begin{array}{l}\text { Adult female } \\
\text { mass }(g)\end{array}$ & No. of eggs & $\begin{array}{l}\text { No. of yolking } \\
\text { follicles }>2 \mathrm{~mm}\end{array}$ \\
\hline Anolis carolinensis & - & $3.39(0.16)$ & $1.0(0.00)$ & $1.7(0.12)$ \\
Anolis bahorucoensis & $0.128(0.011)$ & $0.93(0.06)$ & $1.1(0.16)$ & $1.0(0.00)$ \\
Anolis coelestinus & $0.068(0.009)$ & $2.74(0.11)$ & $0.9(0.11)$ & $1.0(0.00)$ \\
Anolis cybotes & $0.066(0.012)$ & $3.76(0.32)$ & $0.9(0.18)$ & $0.9(0.18)$ \\
Anolis grahami & $0.069(0.008)$ & $2.34(0.14)$ & $0.7(0.15)$ & $0.9(0.10)$ \\
Anolis lineatopus & $0.051(0.011)$ & $2.10(0.12)$ & $0.3(0.15)$ & $0.8(0.10)$ \\
Anolis olssoni & $0.078(0.021)$ & $0.85(0.09)$ & $0.3(0.15)$ & $0.8(0.13)$ \\
Anolis valencienni & $0.074(0.015)$ & $2.79(0.20)$ & $0.7(0.15)$ & $0.7(0.21)$ \\
\hline
\end{tabular}

RCM is not reported for $A$. carolinensis because the 'wet' mass of reproductive tissues was not measured for this species (see text).

$\mathrm{RCM}$, relative clutch mass. breeding season depending on their reproductive load, whereas others may not; such variation across species may hide possible associations between the two variables. Associations between reproductive load and particular behaviors may not be common, or reproduction may only occur when resources are sufficient for parents to avoid substantial costs (Reznick 1985). In Lacerta vivipara, females experience considerably higher survival over the breeding season than males, suggesting that gravidity does not make females particularly vulnerable (Bauwens $\delta$ Thoen 1981), although this study did not include the critical comparison with non-reproductive females. Additionally, the effects of gravidity on skink (Lampropholis guichenoti) locomotion were less than the hindering effects of a moderate increase in body temperature, a large meal, or tail autotomization (Shine 2003b). These results suggest that the cost of locomoting while gravid need not impose a strong selective pressure (Shine 2003b). It is also possible that behavioral modifications are required only for low-quality females, as high-quality females can successfully reproduce while simultaneously performing all needed behaviors. In a wide variety of taxa, females with the highest reproductive output also have increased survival rates (reviewed in Reznick 1985; Olsson et al. 2001).

\section{Methodological Considerations}

Finally, it is important to consider whether associations between reproductive load and behavior (or lack thereof) may result from unrepresentative behavioral observations or low statistical power. In our intraspecific examination of $A$. carolinensis, each female was observed during only one day, and if an individual experienced unusual conditions in its physical or social environment, she may not have behaved in a manner representative of her reproductive status. Our results show strong relationships between gravidity and both locomotor and social display behavior, suggesting that this explanation is unlikely for these behaviors, but may explain the lack of relationship between reproductive load and prey capture rates. The behavioral data in our interspecific analysis are based on repeated observations of each individual and so are robust to this concern.

In addition, our observed statistical power (range $=0.2-0.5$, calculated from effect sizes in Table 3 using G*Power 3.1 (Faul et al. 2009)) could potentially account for the lack of relationships between the evolution of reproductive load and behavior across anole species. However, the clear differences between the patterns in these traits between the within- and among-species analyses provide considerable support that species-level differences in ecology are more likely to account for the evolution of variation in female behavior than reproductive load.

\section{Conclusions}

In conclusion, while we find clear associations among locomotion and display behavior and gravidity within $A$. carolinensis, it does not appear that associations among these traits have evolved at the generic level. Thus, our study indicates that the extensive behavioral variation across Anolis species is not the result of variation in egg mass or volume across these species. Future comparative studies of female behavior and reproductive load, in anoles and other taxa, will be required to directly assess the role of ecology in the evolution of behavioral variation and the generality of the behavioral costs of reproduction. 


\section{Acknowledgements}

We thank Camilla Peabody for technical advice and Tonia Hsieh for field assistance. We also thank Troy Murphy, Kevin McIntyre, and the behavior reading group at Trinity University for comments on a manuscript draft. We are grateful for the support of Jean Lafitte National Park and Danny Horton in Louisiana; Circle B Farm, Discovery Bay Marine Laboratory, and Kemar Gaynor in Jamaica; and Coralsol Beach Resort in the Dominican Republic. This work was supported by a Michigan State University Provost Office Postdoctoral Fellowship to MAJ, a MSU McNair/Summer Research Opportunities Program fellowship to JRV, and NSF IOS-0742833 to JW.

\section{Literature Cited}

Andrews, R. \& Rand, A. S. 1974: Reproductive effort in anoline lizards. Ecology 55, 1317-1327.

Angilletta, M. J. Jr \& Sears, M. W. 2000: The metabolic cost of reproduction in an oviparous lizard. Funct. Ecol. 14, 39-45.

Bauwens, D. \& Thoen, C. 1981: Escape tactics and vulnerability to predation associated with reproduction in the lizard Lacerta vivipera. J. Anim. Ecol. 50, 733-743.

Brodie, E. D. III 1989: Behavioral modification as a means of reducing the cost of reproduction. Am. Nat. 134, 225-238.

Cox, R. M. \& Calsbeek, R. 2010: Severe costs of reproduction persist in Anolis lizards despite the evolution of a single-egg clutch. Evolution 64, 798-809.

Faul, F., Erdfelder, E., Buchner, A. \& Lang, A.-G. 2009: Statistical power analyses using $G^{*}$ Power 3.1: tests for correlation and regression analyses. Behav. Res. Methods 41, 1149-1160.

Felsenstein, J. 1985: Phylogenies and the comparative method. Am. Nat. 125, 1-15.

Fitch, H. S. \& Henderson, R. W. 1987: Ecological and ethological parameters in Anolis bahorucoensis, a species having rudimentary development of the dewlap. Amphib.-Reptil. 8, 69-80.

Garland, T., Harvey, P. H. \& Ives, A. R. 1992: Procedures for the analysis of comparative data using phylogenetically independent contrasts. Syst. Biol. 41, 18-32.

Goodman, B. A. 2006: Costs of reproduction in a tropical invariant-clutch producing lizard (Carlia rubrigularis). J. Zool. 270, 236-243.

Johnson, M. A. 2007: Behavioral ecology of Caribbean Anolis lizards: a comparative approach. PhD thesis, Washington Univ., St. Louis.

Johnson, M. A. \& Wade, J. 2010: Courtship systems across nine Anolis lizard species: sexual dimorphisms in structure and function. Proc. R. Soc. Lond. B Biol. Sci. 277, 1711-1719.

Johnson, M. A., Leal, M., Schettino, L. R., Lara, A. C., Revell, L. J. \& Losos, J. B. 2008: A phylogenetic perspective on foraging mode evolution and habitat use in West Indian Anolis lizards. Anim. Behav. 75, 555-563.

Johnson, M. A., Revell, L. J. \& Losos, J. B. 2010: Behavioral convergence and adaptive radiation: effects of habitat use on territorial behavior in Anolis lizards. Evolution 64, 1151-1159.

Kratochvíl, L. \& Kubička, L. 2007: Why reduce clutch size to one or two eggs? Reproductive allometries reveal different evolutionary causes of invariant clutch size in lizards. Funct. Ecol. 21, 171-177.

Lecomte, J., Clobert, J. \& Massot, M. 1993: Shift in behaviour related to pregnancy in Lacerta vivipera. Rev. Ecol. (la Terre et la Vie) 48, 99-107.

Licht, P. \& Gorman, G. C. 1970: Reproductive and fat cycles in Caribbean Anolis lizards. Univ. Calif. Publ. Zool. 95, 1-52.

Lin, C. X., Zhang, L. \& Ji, X. 2008: Influence of pregnancy on locomotor and feeding performances of the skink, Mabuya multifasciata: why do females shift thermal preferences when pregnant? Zoology 111, $188-195$.

Losos, J. B. 1992: The evolution of convergent community structure in Caribbean Anolis lizards. Syst. Biol. 41, 403-420.

Losos, J. B. 2009: Lizards in an Evolutionary Tree: Ecology and Adaptive Radiation of Anoles. Univ. of California Press, Berkeley.

Miles, D. B., Sinervo, B. \& Frankino, W. A. 2000: Reproductive burden, locomotor performance, and the cost of reproduction in free ranging lizards. Evolution 54, 1386-1395.

Miles, D. B., Losos, J. B. \& Irschick, D. J. 2007: Morphology, performance, and foraging mode. In: Lizard Ecology: The Evolutionary Consequences of Foraging Mode (Reilly, S. M., McBrayer, L. D. \& Miles, D. B., eds). Cambridge Univ. Press, Cambridge, pp. 49-93.

Munns, S. \& Daniels, C. 2007: Breathing with big babies: ventilation and oxygen consumption during pregnancy in the lizard Tiliqua rugosa. Physiol. Biochem. Zool. 80, $35-45$.

Nicholson, K. E., Glor, R. E., Kolbe, J. J., Larson, A., Hedges, S. B. \& Losos, J. B. 2005: Mainland colonization by island lizards. J. Biogeogr. 32, 929-938.

Nunez, S. C., Jenssen, T. A. \& Ersland, K. 1997: Female activity profile of a polygynous lizard (Anolis carolinensis): evidence of intersexual asymmetry. Behaviour 134, 205-223.

Olsson, M., Shine, R. \& Bak-Olsson, E. 2000: Locomotor impairment of gravid lizards: is the burden physical or physiological? J. Evol. Biol. 13, 263-268. 
Olsson, M., Shine, R. \& Wapstra, E. 2001: Costs of reproduction in a lizard species: a comparison of observational and experimental data. Oikos 92, $121-125$.

Preston, F. W. 1974: The volume of an egg. Auk 91, 132-138.

Revell, L. J. 2006: IDC: a program for the calculation of independent contrasts. Available at: http://anolis.oeb. harvard.edu/ liam/programs/.

Reznick, D. 1985: Costs of reproduction: an evaluation of the empirical evidence. Oikos 44, 257-267.

Rodewald, A. D. \& Foster, S. A. 1998: Effects of gravidity on habitat use and antipredator behaviour in threespined sticklebacks. J. Fish Biol. 52, 973-984.

Roff, D. L. 1992: The Evolution of Life Histories - Theory and Analysis. Chapman \& Hall, New York.

Rosenheim, J. A. 1999: The relative contributions of time and eggs to the cost of reproduction. Evolution 53, 376-385.

Sanderson, M. J. 2003: r8s; inferring absolute rates of evolution and divergence times in the absence of a molecular clock. Bioinformatics 19, 301-302.

Sanger, T. J., Hime, P. M., Johnson, M. A., Diani, J. \& Losos, J. B. 2008: Laboratory protocols for husbandry and embryo collection of Anolis lizards. Herpetol. Rev. 39, 58-63.

Scales, J. \& Butler, M. 2007: Are powerful females powerful enough? Acceleration in gravid green iguanas (Iguana iguana). Integr. Comp. Biol. 47, 285-294.

Schwarzkopf, L. \& Shine, R. 1991: Themal biology of reproduction in viviparous skinks, Eulamprus tympanum: why do gravid females bask more? Oecologia 88 , $562-569$.
Schwarzkopf, L. 1994: Measuring trade-offs: a review of studies of costs of reproduction in lizards. In: Lizard Ecology: Historical and Experimental Perspectives (Vitt, L. J. \& Pianka, E. R., eds). Princeton Univ. Press, Princeton, pp. $1-28$.

Shine, R. 1980: "Costs" of reproduction in reptiles. Oecologia 46, 92-100.

Shine, R. 2003a: Effects of pregnancy on locomotor performance: an experimental study on lizards. Oecologia 136, 450—456.

Shine, R. 2003b: Locomotor speeds of gravid lizards: placing "costs of reproduction" within an ecological context. Funct. Ecol. 17, 526-533.

Sinervo, B., Hedges, R. \& Adolph, S. C. 1991: Decreased sprint speed as a cost of reproduction in the lizard Sceloporus occidentalis: variation among populations. J. Exp. Biol. 155, 323-336.

Stearns, S. C. 1989: Trade-offs in life history evolution. Funct. Ecol. 3, 259-268.

Weeks, S. C. 1996: The hidden cost of reproduction: reduced food intake caused by spatial constraints in the body cavity. Oikos 75, 345-349.

Weiss, S. L. 2001: The effect of reproduction on food intake of a sit-and-wait foraging lizard, Sceloporus virgatus. Herpetologica 57, 138-146.

Williams, E. E. 1983: Ecomorphs, faunas, island size, and diverse end points in island radiations of Anolis. In: Lizard Ecology (Huey, R. B., Pianka, E. R. \& Schoener, T. W., eds). Harvard Univ. Press, Cambridge, pp. 326-370.

Zani, P. A., Neuhaus, R. A., Jones, T. D. \& Milgrom, J. E. 2008: Effects of reproductive burden on endurance performance in side-blotched lizards (Uta stansburiana). J. Herpetol. 42, 76-81. 